\title{
Hubungan Personal Higiene dengan Kejadian Infeksi Cacing Soil Transmitted Helminth pada Petani di Desa Besuk Kecamatan Gurah Kabupaten Kediri Tahun 2018
}

\author{
Reny Nugraheni ${ }^{1}$, Siska Kusuma Wardani ${ }^{1}$, M. Imun ${ }^{2}$ \\ ${ }^{1}$ Fakultas Ilmu Kesehatan \\ ${ }^{2}$ Institut Ilmu Kesehatan Bhakti Wiyata Kediri \\ Email: reny.nugraheni@IIK.ac.id
}

Received 31 August 2018; Accepted 1 September 2018; Published 6 November 2018

\begin{abstract}
ABSTRAK
Latar Belakang : Infeksi kecacingan yang disebabkan oleh Soil Transmitted Helminth (STH) merupakan masalah kesehatan masyarakat Indonesia. Dalam melakukan pekerjaannya petani di Desa Besuk Kecamatan Gurah ada yang tidak memakai alas kaki dan dalam bekerja di sawah bekerja tanpa menggunakan sarung tangan. Kebersihan perorangan masih kurang. Hal ini dapat dilihat dari kebiasaan petani yang setelah bekerja tidak mencuci tangan terlebih dahulu sebelum makan. Keadaan yang seperti itu dapat mempermudah timbulnya kecacingan pada petani. Tujuan : Mengetahui hubungan antara personal higiene dengan kejadian infeksi 'Soil Transmitted Helminth' pada petani di Desa Besuk Kecamatan Gurah Kabupaten Kediri”. Metode : Jenis penelitian yang di gunakan adalah metode survei analitik menggunakan pendekatan cross sectional pengumpulan data menggunakan kuesioner dan wawancara mendalam. Hasil : Berdasarkan wawancara dan observasi langsung yang dilakukan di desa Besuk, bahwa Personal Higiene Petani Desa Besuk adalah tidak baik sebanyak 58 responden $(96,67 \%)$, dan petani yang positif terinfeksi sebanyak 57 responden $(95 \%)$. Sehingga ada hubungan antara personal higiene dan infeksi cacing soil Transmitted Helminth pada petani desa Besuk. Kesimpulan dan saran : ada hubungan antara personal higiene dan infeksi cacing soil Transmitted Helminth pada petani desa Besuk. Sehingga penting bagi petani untuk menjaga personal higiene terutama setelah bekerja dan sebelum makan dengan cara mencuci tangan dan kaki.
\end{abstract}

Kata kunci: Personal higien, infeksi cacing Soil Transmitted Helminth

Copyright $\odot 2018$ STIKes Surya Mitra Husada

All right reserved.

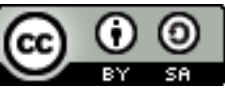

This is an open-acces article distributed under the terms of the Creative Commons AttributionShareAlike 4.0 International License.

\section{PENDAHULUAN}

Infeksi kecacingan yang disebabkan oleh Soil Transmitted Helminth (STH) merupakan masalah kesehatan masyarakat Indonesia. Infeksi kecacingan tergolong penyakit infeksi yang kurang diperhatikan dan bersifat kronis tanpa menimbulkan gejala klinis yang jelas dan dampak yang ditimbulkannya baru terlihat dalam jangka panjang. Beberapa dampak yang disebabkan oleh cacing seperti kekurangan gizi, gangguan tumbuh kembang dan gangguan kognitif pada anak, dan apabila pada orang dewasa akan menurunkan produktifitas kerja (Kurniawan, 2010). Infeksi cacing pada umumnya masuk melalui mulut, atau langsung melalui luka di kulit. Cacing yang masuk dapat berupa 
telur, kista atau larva, yang ada di atas tanah terutama bila pembuangan kotoran atau tinja dilakukan dengan menggunakan sistem terbuka dan tidak memenuhi persyaratan hyginis (Zulkoni, 2011).

Jenis cacing STH yang sering menginfeksi adalah Ascaris lumbricoides (cacing gelang), Trichuris trichiura (cacing cambuk), Necator americanus dan Ancylostoma duodenale (cacing tambang) ini disebabkan oleh karena kebiasaan dan perilaku yang tidak bersih misalnya; tidak mencuci tangan sebelum makan, kuku tangan panjang dan tidak pernah memakai alas kaki jika sedang melakukan aktifitas sehingga kebersihan kurang diperhatikan (Rawina, 2012).

Prevalensi cacing tersebut tinggi terjadi didaerah tropis, karena telur dan larva cacing lebih dapat berkembang di tanah yang hangat, basah atau lembab. Perilaku juga memberikan kontribusi terhadap kejadian cacing misalnya hygiene dan sanitasi yang rendah pada suatu komuditas atau kelompok masyarakat (Irianto, 2013).

Insidens tinggi ditemukan pada penduduk Indonesia, terutama di daerah pedesaan, khususnya pada petani. Seringkali golongan petani yang langsung berhubungan dengan tanah, mendapat infeksi lebih dari $70 \%$. Kebiasaan defekasi di tanah/sungai dan pemkaian kotoran sebagai pupuk penting dalam penyebaran infeksi. Penularan Nematoda STH tidak hanya menular melalui tanah tetapi dapat melalui kotoran. Mekanisme penularan STH berkaitan dengan hygiene dan sanitasi lingkungan yang buruk, aspek sosial ekonomi dan tingkat pengetahuan seseorang (Widoyono, 2011).

Berdasarkan survei awal pada bulan Mei 2017, dalam melakukan pekerjaannya petani di Desa Besuk Kecamatan Gurah ada yang tidak memakai alas kaki dan dalam bekerja di sawah bekerja tanpa menggunakan sarung tangan. Kebersihan perorangan masih kurang. Hal ini dapat dilihat dari kebiasaan petani yang setelah bekerja tidak mencuci tangan terlebih dahulu sebelum makan. Keadaan yang seperti itu dapat mempermudah timbulnya kecacingan pada petani.

Berdasarkan uraian diatas, penulis ingin melakukan penelitian tentang "Hubungan Antara Personal Higiene dengan Kejadian Infeksi 'Soil Transmitted Helminth' pada Petani di Desa Besuk Kecamatan Gurah Kabupaten Kediri”.

\section{METODE PENELITIAN}

Desain penelitian yang digunakan dalam penelitian ini adalah metode observasi dengan survei analitik menggunakan pendekatan cross sectional yaitu peneliti mempelajari tentang personal higiene dan infeksi cacing Soil Transmitted Helmint dengan melakukan pengukuran sesaat atau pada saat yang bersamaan dan dilakukan satu kali saja (Notoatmodjo, 2010). Populasi adalah keseluruhan objek penelitian atau yang diteliti (Kuntoro, 2010). Serta populasi yang telah ditetapkan oleh peneliti yaitu petani di desa Besuk. Jumlah sample dalam penelitian ini adalah 60 responden.

\section{HASIL DAN PEMBAHASAN}

\section{Hasil}

\section{Personal Higiene Petani Desa Besuk}

Berdasarkan hasil penelitian diperoleh total skor personal higiene pada petani di Desa Besuk Kecamatan Gurah Kabupaten Kediri berkisar antara $1-8$ dengan rata-rata skor 3,37 sedangkan standar deviasi sebesar 1,97. Jika hasil dari skoring tersebut dikelompokkan menjadi 2 kategori yaitu tidak baik dan baik maka dapat dilihat dalam tabel berikut ini.

Tabel 2.1 Personal Higiene Petani Desa Besuk

\begin{tabular}{ccc}
\hline Personal Higiene & Frekuensi $\mathbf{( F )}$ & Presentase $(\boldsymbol{\%})$ \\
\hline Tidak Baik & 58 & 96,67 \\
\hline Baik & 2 & 3,33 \\
\hline Jumlah & 60 & 100 \\
\hline
\end{tabular}

Sumber : data primer, 2018 
Proporsi yang paling banyak adalah tidak baik sebanyak 58 responden $(96,67 \%)$ dibandingkan dengan yang memiliki personal higiene yang baik sebanyak 2 responden $(3,33 \%)$.

\section{Infeksi Cacing Soil Transmitted Helminth}

Berdasarkan hasil penelitian variabel Infeksi Cacing Soil Trasmitted Helminth dikategorikan menjadi dua yaitu negative dan positif yang dapat dilihat dalam tabel berikut ini.

Tabel 2.2 Infeksi Cacing Soil Transmitted Helminth Petani Desa Besuk

\begin{tabular}{ccc}
\hline Infeksi Cacing & Frekuensi (F) & Presentase (\%) \\
\hline Negatif & 3 & 5 \\
\hline Positif & 57 & 95 \\
\hline Jumlah & 60 & 100 \\
\hline
\end{tabular}

Proporsi yang paling banyak adalah positif terinfeksi sebanyak 57 responden (95\%) dibandingkan dengan yang negatif / tidak terinfeksi sebanyak 3 responden (5\%).

\section{Hubungan Personal Higiene Dengan Kejadian Infeksi Cacing Soil Transmitted Helminth Pada Petani Di Desa Besuk Kecamatan Gurah Kabupaten Kediri.}

Berdasarkan hasil penelitian variabel Infeksi Cacing Soil Trasmitted Helminth dikategorikan menjadi dua yaitu negative dan positif yang dapat dilihat dalam tabel berikut ini.

Tabel 2.2 Infeksi Cacing Soil Transmitted Helminth Petani Desa Besuk

\begin{tabular}{|c|c|c|c|c|c|}
\hline & & & \multicolumn{2}{|c|}{ Infeksi Cacing } & \multirow{2}{*}{ Total } \\
\hline & & & $(+)$ & $(-)$ & \\
\hline \multirow{4}{*}{ Personal Higiene } & \multirow{2}{*}{ Baik } & $\mathrm{N}$ & 0 & 2 & 2 \\
\hline & & $\%$ & 0 & 3,3 & 3,3 \\
\hline & \multirow{2}{*}{ Tidak Baik } & $\mathrm{N}$ & 57 & 1 & 58 \\
\hline & & $\%$ & 95,0 & 1,7 & 96,7 \\
\hline \multirow{2}{*}{ Total } & & $\mathrm{N}$ & 57 & 3 & 60 \\
\hline & & $\%$ & 95,0 & 5,0 & 100 \\
\hline \multicolumn{2}{|c|}{ Uji Fisher } & & & $02(1$ & \\
\hline
\end{tabular}

Tabel ini menunjukan hasil uji Fisher $\mathrm{P}=0,002(\mathrm{P}<0,05)$. Maka dapat disimpulkan bahwa ada hubungan antara personal higiene dengan infeksi cacing Soil Transmitted Helmint.

\section{Pembahasan}

Dari hasil penelitian yang telah diperoleh, dapat dilakukan pembahasan sebagai berikut :

\section{Personal Higiene Petani Desa Besuk}

Dari penelitian didapatkan data yaitu responden yang mempunyai tingkat kebersihan perorangan yang baik dengan kejadian infeksi Soil Transmitted Helminth yang negative sebanyak 3 responden (5\%) lebih banyak dibandingkan dengan kejadian infeksi Soil Transmitted Helminth yang positif sebanyak 57 responden (95\%). Hal ini memberikan gambaran bahwa personal hygiene yang baik akan mengurangi terjadinya infeksi Soil Transmitted Helminth pada tubuh orang. Maka untuk mengurangi terjadinya infeksi Soil Transmitted Helminth maka dapat dilakukan dengan cara selalu menjaga kebersihan perorangan 


\section{Infeksi Cacing Soil Transmitted Helminth}

Dari penelitian didapatkan data yaitu Proporsi yang paling banyak adalah positif terinfeksi sebanyak 57 responden (95\%) dibandingkan dengan yang negatif / tidak terinfeksi sebanyak 3 responden (5\%). Maka untuk mengurangi terjadinya infeksi Soil Transmitted Helminth maka dapat dilakukan dengan cara selalu menjaga kebersihan perorangan dengan cara : (1) Cuci tangan sebelum makan, sehabis bekerja dan sehabis BAB untuk memotong rantai terkontaminasinya tangan dengan kotoran manusia. (2). Tersedianya samijaga yang sehat (sarana air minum dan jamban yang sehat), untuk memotong rantai penularan terhadap air, makanan (sayur - sayuran), minuman dan pencemaran tanah oleh kotoran manusia. (3). Perlindungan terhadap pencemaran sumber mata air, makanan dan minuman dilakukan dengan pemberdayaan perilaku sehat pemakai air dan melindungi atau memberantas sumber pencemaran. Kuku sebaiknya selalu dipotong pendek untuk menghindari penularan cacing dari tangan ke mulut (Kumoro, 2014).

\section{Hubungan Personal Higiene Dengan Kejadian Infeksi Cacing Soil Transmitted Helminth Pada Petani Di Desa Besuk Kecamatan Gurah Kabupaten Kediri.}

Kebersihan perorangan atau hygiene perorangan disebut juga personal hygiene, yang berarti kebersihan. Hygiene perorangan adalah suatu upaya kesehatan perorangan untuk memelihara kesehatan diri sendiri guna membentuk sumber daya yang handal dan berkualitas. Berdasarkan hasil penelitian diperoleh hasil bahwa dari 60 responden, yang mempunyai tingkat kebersihan persorangan yang tidak baik sebanyak 58 responden dengan kejadian infeksi Soil Transmitted Helminth yang positif sebanyak 57 responden (95\%) dibandingkan yang infeksi Soil Transmitted Helminth yang negative sebanyak 3 responden (5\%). Hal ini memberikan gambaran bahwa kebersihan persorangan (personal Hygiene) mengakibatkan akan terjadinya infeksi Soil Transmitted Helminth. Penyebaran infeksi Soil Transmitted Helminth dapat melalui terkontaminasinya tanah.

\section{SIMPULAN DAN SARAN}

\section{Simpulan}

Dari hasil penelitian yang dilakukan di Desa Besuk yaitu :

1. Proporsi yang paling banyak adalah tidak baik sebanyak 58 responden $(96,67 \%)$ dibandingkan dengan yang memiliki personal higiene yang baik sebanyak 2 responden (3,33\%).

2. Proporsi yang paling banyak adalah positif terinfeksi sebanyak 57 responden (95\%) dibandingkan dengan yang negatif / tidak terinfeksi sebanyak 3 responden (5\%).

3. Ada hubungan antara kebersihan perorangan dengan angka kejadian infeksi Soil Transmitted Helminth pada petani desa Besuk Kecamatan Gurah Kabupaten Kediri.

\section{Saran}

Saran yang dapat disampaikan berdasarkan hasil penelitian ini adalah :

1. Melakukan upaya pengobatan bagi petani desa Besuk yang terinfeksi cacing soil transmitted helmint dengan mengkonsumsi obat cacing sesuai dosis.

2. Memberikan informasi atau penyuluhan kepada petani tentang personal higiene untuk mencegah resiko infeksi cacing soil transmitted helmint.

3. Untuk petani agar selalu menjaga personal higiene terutama kaki dan tangan setelah bekerja dari sawah dan sebelum makan. 
Hubungan Personal Higiene dengan Kejadian Infeksi Cacing Soil Transmitted Helminth.....

\section{DAFTAR PUSTAKA}

Irianto, K. (2013). Parasitologi Medis. Bandung: Alfabeta.

Kuntoro, H. (2010). Metode Sampling dan Penentuan Besar Sampel. Surabaya: Penerbit Pustaka Melati Surabaya.

Kepmenkes RI. (2006). Pedoman Pengendalian Cacingan Nomor 424/MENKES/SK/VI/2006. Menteri Kesehatan Republik Indonesia.

Kumoro, A. (2014). Parasitologi Praktikum Analis Kesehatan. Jakarta: Penerbit Buku Kedokteran EGC.

Kurniawan, A. (2010). Infeksi Parasit: Dulu dan Masa Kini. Majalah Kedokteran Indonesia.

Notoatmodjo. (2012). Metodologi Penelitian Kesehatan. Jakarta: PT Rineka Cipta.

Rawina, W. Mulyati, A. (2012). Hubungan Sanitasi Diri dengan Kejadian Kecacingan pada Siswa SDN X Paseban Jakarta Pusat. Departemen Parasitologi Fakultas Kedokteran Universitas Indonesia: Jakarta.

World Health Organization. (2012). Soil transmitted helminthiases, eliminating soil transmitted helminthiases.

Widoyono, (Ed). (2011). Penyakit Tropis Epidemologi, Penularan, Pencegahan dan Pemberantasannya Edisi Kedua. Jakarta: Erlangga.

Zulkoni, A. (2011). "Parasitologi untuk Keperawatan, Kesehatan Masyarakat, dan Teknik Lingkungan”. Yogyakarta: Nuha Medika. 